\title{
Tailored Jeffamine Molecular Tools for Ordering Mesoporous Silica
}

\begin{tabular}{|r|l|}
\hline Journal: & Langmuir \\
\hline Manuscript ID: & la-2012-01413u.R2 \\
\hline Manuscript Type: & Article \\
\hline Date Submitted by the Author: & $25-$ May-2012 \\
\hline Complete List of Authors: & $\begin{array}{l}\text { May, Anna; Barcelona University, Chemical Engineering } \\
\text { Pasc, Andreea; Universite Henri Poincare, Faculte des Sciences et } \\
\text { Techniques } \\
\text { Stebe, Marie Jose } \\
\text { Gutierrez, Jose; Universidad de Barcelona, Ingenieria Quimica } \\
\text { Porras, Montserrat; University of Barcelona, Chemical engineering } \\
\text { Blin, Jean-Luc; University of Nancy-1, Equipe Physicochimie des Colloïdes }\end{array}$ \\
\hline
\end{tabular}

\section{SCHOLARONE ${ }^{\text {ix }}$}

Manuscripts 


\title{
Tailored Jeffamine Molecular Tools for Ordering Mesoporous Silica
}

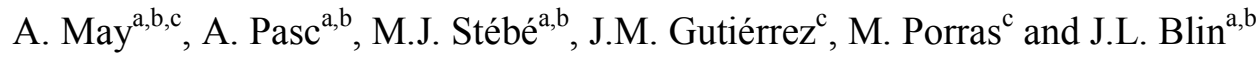 \\ ${ }^{\mathrm{a}}$ :Université de Lorraine/CNRS, SRSMC, UMR7565, F-54506 Vandoeuvre-lès-Nancy cedex, \\ France \\ ${ }^{\mathrm{b}}$ : CNRS, UMR7565, F-54506 Vandoeuvre-lès-Nancy cedex, France \\ ':Departament d'Enginyeria Química, Facultat de Química, Universitat de Barcelona, Martí i \\ Franquès 1-11, 08028, Barcelona, Catalunya, Spain
}

\begin{abstract}
Herein, we report the formation of organized mesoporous silica materials prepared from a novel nonionic gemini surfactant, myristoyl-end capped Jeffamine, synthesized from a polyoxyalkyleneamine (ED900). The behavior of the modified Jeffamine in water was first investigated. A direct micellar phase $\left(\mathrm{L}_{1}\right)$ and a hexagonal $\left(\mathrm{H}_{1}\right)$ liquid crystal were found. The structure of the micelles was investigated from the SAXS and the analysis by Generalized Indirect Fourier Transformation (GIFT), which show that the particles are globular of coreshell type. The myristoyl chains, located at the ends of the amphiphile molecule are assembled to form the core of the micelles and, as a consequence, the molecules are folded over on themselves.

Mesoporous materials were then synthesized from the self-assembly mechanism. The recovered materials were characterized by SAXS measurements, nitrogen adsorptiondesorption analysis, transmission and scanning electron microscopy. The results clearly evidence that by modifying the synthesis parameters, such as the surfactant/silica precursor molar ratio and the hydrothermal conditions, one can control the size and the nanostructuring of the resulting material. It was observed that, the lower the temperature of the hydrothermal treatment, the better the mesopore ordering.
\end{abstract}




\section{Introduction}

Since their discovery in the early nineties, ordered mesoporous materials have attracted much research attention due to a number of remarkable properties such as the adjustable pore size, the high surface area, pore volume and the ease of surface modification ${ }^{1,2}$. These characteristics afford their use for several potential applications in many fields such as adsorbents, catalysts, host matrixes for electronic and photonic devices, drug delivery and sensors $^{3-8}$. The synthesis of these compounds combines the sol-gel chemistry and the use of assemblies of amphiphilic molecules, mainly surfactants, as framework templates. Depending on the surfactant concentration, two mechanisms can lead to the formation of the ordered material. The first one is the self-assembly mechanism (CTM): in this case the building blocks are the micelles, so the CTM occurs at low surfactant concentrations ${ }^{9-13}$. The second approach to the preparation of ordered mesostructures utilizes a liquid crystal phase and it is labeled as the direct liquid crystal templating (LCT) pathway ${ }^{14-18}$. The inorganic precursors grow around the liquid crystal. After the polymerization and the condensation, the template can be removed, leaving a mesoporous material, whose structure, pore size and symmetry are determined by the liquid crystal scaffold. In addition, the high surfactant concentration templating method often leads to monolithic materials rather than powders, which are associated with mesostructured silica prepared from a micellar solution. Numerous surfactantbased systems have been investigated as structure directing agents, in particular the nonionic ones $^{9,19}$. As a matter of fact, a large number of nonionic surfactants widely used in industries and featured with low cost, low toxicity and bio-degradation can be utilized as templates for the design of mesoporous materials. For example, using polyoxyethylene alkyl ethers $\left[\mathrm{C}_{\mathrm{m}}(\mathrm{EO})_{\mathrm{n}}\right]$, a series of compounds labeled $\mathrm{SBA}^{10,20}$ (Santa Barbara), MSU${ }^{21,22}$ (Michigan State University) have been prepared. Several groups have also demonstrated the ability of fluorinated surfactants to be used for the mesostructured silica preparation ${ }^{18,23-27}$. For 
instance, we have synthesized mesoporous materials by using nonionic fluorinated surfactants $\left[\mathrm{R}_{\mathrm{m}}^{\mathrm{F}}(\mathrm{EO})_{\mathrm{n}}\right]^{18,23,24}$, which are the fluorinated analogues of the hydrogenated polyoxyethylene alkyl ethers $\left[\mathrm{C}_{\mathrm{m}}(\mathrm{EO})_{\mathrm{n}}\right]$. As regards the synthesis of mesoporous molecular sieves, the main advantage of fluorinated surfactants compared to the hydrogenated ones is their high thermal stability. Indeed, this property enables making the hydrothermal treatment at higher temperatures, leading to a better condensation of silica and resulting in a material with improved hydrothermal stability ${ }^{28}$. The examples reported above deal with low molecular weight surfactants and, except the block copolymers ones, the use of amphiphilic polymers of larger molecular weight is scarcer ${ }^{29-35}$. Among the block copolymer-templated materials, SBA-15 is the most widely studied one. SBA-15 has been discovered in 1998 by Stucky et al. and it is prepared under strong acidic conditions by using micelles of Pluronic P123 $\left[(\mathrm{EO})_{20}(\mathrm{PO})_{70}(\mathrm{EO})_{20}\right]^{29}$ as template. More recently silica mesostructues have been synthesized using diamine polypropylene amphiphiles that belong to the Jeffamine family. Indeed Pinnavaia et al. have reported the preparation of a new group of large pore mesoporous silicas, denoted MSU-J ${ }^{36,37}$. The materials are obtained through hydrogen-bonding pathways from sodium silicate or tetraethylorthosilicate as the silica source and amine-terminated Jeffamine as the structure-directing agent. Depending on the synthesis conditions, the pore size and the specific surface area varied respectively from 4.9 to $14.3 \mathrm{~nm}$ and from 108 to $1127 \mathrm{~m}^{2} / \mathrm{g}$. MSU-J represent the largest pore sizes observed to date for a fully threedimensional mesoporous framework assembled from a single micellar porogen. However, no mesopore ordering is noted for MSU-J, the materials exhibit a wormhole-like framework. Mesoporous silicas with onion-like morphology were also synthesized with the same family of amphiphile by Sayari et al. ${ }^{38}$ Until now no hexagonal mesopore ordering has been obtained with the Jeffamine family. Our group has also tried to prepare mesoporous materials through the assembly of $\mathrm{H}_{2} \mathrm{~N}-(\mathrm{PO})_{3}(\mathrm{EO})_{12.5}(\mathrm{PO})_{3} \mathrm{NH}_{2}$ (Jeffamine ED900) and tetramethoxysilane but 
no templated materials could be recovered, we obtained only the precipitated silica. In this paper, we have modified ED900 to obtain gemini surfactants in order to decrease the high hydrophilicity of ED900. Then, we have investigated the ability of the modified Jeffamine to be used for the preparation of ordered mesoporous materials. As the properties of the molecular sieves depend on the phase behavior of the structure directing agent in the synthesis solvent, in a first part we have determined the phase diagram of the modified Jeffamine in water.

\section{Materials and methods}

$\mathrm{H}_{2} \mathrm{~N}-(\mathrm{PO})_{3}(\mathrm{EO})_{12.5}(\mathrm{PO})_{3} \mathrm{NH}_{2}$ (trade name Jeffamine ED900 (XTJ-501)) was supplied by Huntsman Corporation. It is based on a polyether $(\mathrm{PO})_{\mathrm{x}}-(\mathrm{EO})_{\mathrm{y}}-(\mathrm{PO})_{\mathrm{z}}$ backbone containing primary amino groups attached at both ends and it is presented as a transparent viscous liquid at ambient temperature. Myristic acid and tetramethoxysilane (TMOS), used as silica source, were purchased from Sigma-Aldrich. Deionized water was obtained using a Milli-Q water purification system.

Modification of ED900: A mixture of Jeffamine ED900 (2 g, $2.1 \mathrm{mmol})$ and myristic acid $(1.015 \mathrm{~g}, 4.4 \mathrm{mmol})$ was heated under microwaves $(50 \mathrm{~W})$ for 8 minutes. The reaction mixture was then cooled to room temperature and the product, named ED900Myr, was used without further purification. The reaction yield was $100 \%$. Surfactant concentrations presented here take into account the water content of the batch, $1.3 \%(\mathrm{w} / \mathrm{w})$, formed during the reaction. ${ }^{1} \mathbf{H}-\mathbf{N M R}\left(\mathbf{C D}_{3} \mathbf{O D}\right): 0.89\left(\mathrm{t}, 6 \mathrm{H}, \underline{\mathrm{CH}}_{3}-\mathrm{CH}_{2}, \mathrm{~J}=6.5 \mathrm{~Hz}\right) ; 1.11\left(\mathrm{~m}, 18 \mathrm{H}, \underline{\mathrm{CH}}_{3}-\mathrm{CH}\right)$; 1.25 (m, $40 \mathrm{H}, \underline{\mathrm{CH}_{2}}$-alkyl chain); 1.59 (m, $4 \mathrm{H}, \underline{\mathrm{CH}_{2}}$ in $\beta$ of $\mathrm{CO}$ group); 2.17 (t, $4 \mathrm{H}, \underline{\mathrm{CH}_{2}}$ in $\alpha$ of

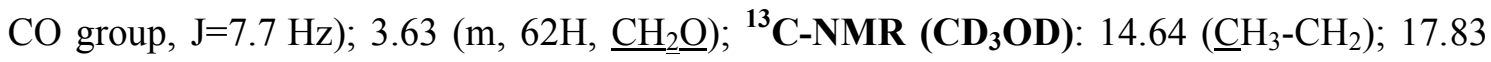
and $17.86\left(\underline{\mathrm{CH}}_{3}-\mathrm{CH}\right) ; 23.86,27.21,27.57,30.41,30.6,30.75,30.78,30.87$ and $30.91\left(\underline{\mathrm{CH}}_{2}-\right.$ alkyl chain); 33.19 ( $\underline{\mathrm{CH}}_{2}$ in $\beta$ of $\mathrm{CO}$ group); 37.29 and 37.33 ( $\underline{\mathrm{CH}_{2}}$ in $\alpha$ of $\mathrm{CO}$ group); 48.72 
and $48.94\left(\mathrm{CH}_{3}-\underline{\mathrm{CH}}\right) ; 71.68,76.21,76.47,76.55$ and $76.84\left(\underline{\mathrm{CH}}_{2}-\mathrm{O}\right) ; 175.71$ and 176.21 (CONH). FTIR: $3292 \mathrm{~cm}^{-1}\left(v_{\mathrm{NH}}\right), 1644 \mathrm{~cm}^{-1}\left(v_{\mathrm{CO}}\right), 1538\left(\delta_{\mathrm{NH}}\right)$. Elemental analysis: $\mathrm{C}_{74} \mathrm{H}_{148} \mathrm{~N}_{2} \mathrm{O}_{20.5}$, th. \%C: $63.79, \% \mathrm{H}: 10.63, \% \mathrm{~N}: 2.01$, exp. \%C: $62.64, \% \mathrm{H}: 10.33, \% \mathrm{~N}: 2.01$. Infrared (IR) spectra were recorded on a Perkin-Elmer FTIR "spectrum one", in ATR mode. Nuclear magnetic resonance (NMR) spectra were recorded on a Bruker AM 400 instrument. Chemical shifts are reported in ppm relative to TMS as internal standard.

Phase diagram determination: The phase diagrams have been established by preparing samples over the whole range of surfactant/water compositions. The required amounts of the components were weighed in small glass tubes. The homogenization of the samples was achieved by mixing with a vortex stirrer, combined with heat and ultrasounds, whenever necessary. The samples were placed in a thermostatic bath and, depending on the system, they were allowed to stand from a few hours to several days at the temperature of interest in order to reach equilibrium. The different phases were identified by visual inspection with a polarizing light microscope (Olympus BX 50). The boundary lines of the liquid crystal domains were evidenced by Small Angle X-ray Scattering (SAXS) experiments. Micellar solutions $(0.5$ to $5 \mathrm{wt} \%)$ were used to determine the size of particles by Dynamic light scattering (DLS) with a Malvern 300HSA Zetasizer instrument. The measurements were repeated three times. Surface tension measurements were performed following the Wilhelmy plate method with a Krüss K100 tensiometer.

Mesoporous material preparation: Surfactant micellar solutions were prepared (from 3 to $20 \mathrm{wt} \%$ ). The solution $\mathrm{pH}$ was kept to 7. Tetramethoxysilane (TMOS), used as the silica source, was added dropwise to the surfactant solution at room temperature under stirring. The surfactant/silica molar ratio $(\mathrm{R})$ was varied from 0.05 to 1 . Then, the mixture was transferred into sealed Teflon autoclaves for the hydrothermal treatment, which was essayed at different temperatures (from room temperature to $100{ }^{\circ} \mathrm{C}$ ) and durations (from 24 to 140 hours). After 
the hydrothermal treatment, the material was transferred into cellulose extraction cartridges and left for 48 hours under Soxhlet ethanol extraction to remove the template. Finally, the material was left to air-dry.

Characterization of mesoporous materials: SAXS measurements were carried out using SAXSess mc2 (Anton Paar) apparatus. It is attached to a ID 3003 laboratory X-Ray generator (General Electric), equipped with a sealed X-ray tube (PANalytical, $\left.\lambda_{\mathrm{Cu}(\mathrm{K} \alpha)}=0.1542 \mathrm{~nm}\right)$ operating at $40 \mathrm{kV}$ and $50 \mathrm{~mA}$. A multilayer mirror and a block collimator provide a monochromatic primary beam. A translucent beam stop allows the measurement of an attenuated primary beam at $\mathrm{q}=0$. Mesoporous materials are introduced into a powder cell whereas liquid crystals and micellar solutions are placed, respectively, in a paste cell and in a capillary having a diameter of $1 \mathrm{~mm}$. Samples are placed inside an evacuated chamber. Acquisition times are typically in the range of 1 to 5 minutes. Scattering of X-ray beam is recorded by a CCD detector (Princeton Instruments, 2084 x 2084 pixels array with 24 x $24 \mu \mathrm{m}^{2}$ pixel size) in the q range 0.09 to $5 \mathrm{~nm}^{-1}$. The detector is placed at $309 \mathrm{~mm}$ from the sample holder. Scattering data, obtained with a slit collimation, contain instrumental smearing. Therefore, the beam profile has been determined and used for the desmearing of the scattering data. All data were corrected for the background scattering from the empty cells. For the micellar solutions, the data were corrected from the water filled capillary scattering. Samples for transmission electron microscopy (TEM) analysis were prepared by dispersing some material in ethanol. Afterwards a drop of this dispersion was placed on a holey carbon coated copper grid. A Philips CM20 microscope, operated at an accelerating voltage of 200 $\mathrm{kV}$, was used to record the images. Scanning electron microscopy (SEM) was carried out with a HITACHI S-2500 at $15 \mathrm{keV}$. $\mathrm{N}_{2}$ adsorption and desorption isotherms were determined on a Micromeritics TRISTAR 3000 sorptometer at $-196{ }^{\circ} \mathrm{C}$. The pore diameter and the pore size 
distribution were determined by the BJH (Barret, Joyner, Halenda) ${ }^{39}$ method applied to the adsorption branch of the isotherm.

\section{Results and discussion}

Firstly, the behavior of the ED900 in water was examined. The aqueous solutions of Jeffamine ED900 appeared transparent and isotropic from 0 to $100 \mathrm{wt} \%$. Tensiometry measurements showed that ED900 decreased gradually the surface tension, achieving minimal values around $35 \mathrm{mNm}^{-1}$. No inflection point was observed, indicating the complete solubilization of this substance and no formation of aggregates. Thus, no micelle is formed and, as a consequence, no templated material can be obtained after the addition of the silica precursor. Moreover, no anisotropy was observed by polarizing light microscopy at any concentration. Dynamic light scattering experiments proved that the Jeffamine ED900 does not form micelles in water. This Jeffamine has complete water solubility, basically due to the long ethylene oxide backbone, entrapped between two short propylene oxide moieties. Therefore, the structural modification of the molecule was performed in order to obtain the micelle formation in water and, consequently, enable the synthesis of mesoporous materials through the CTM mechanism.

\subsection{Modification of the Jeffamine ED900}

The synthesis of the gemini surfactant described in the present study is simple and rapid, and the starting materials, myristic acid and Jeffamine ED900, are cost-effective. The grafting of the myristic acid onto the polyetheramine ED900 was performed quantitatively under solventfree conditions using microwave (MW) irradiation. As the starting Jeffamine, the gemini surfactant is polydispersed with respect to both the ethylene oxide and the propylene oxide moieties. ESI-MS was used to verify molar mass information of the sample, provided by 
Hunstman (SI 1). The average values of $\mathrm{x}+\mathrm{z}=6$ and $\mathrm{y}=12.5$ were calculated from the relative abundances of the individual molecular ions. From these values, the number-average molar mass of ED900 was calculated to be 972 and of ED900Myr to be 1392. The polydispersity index (mass-average molar mass divided by the number-average molar mass) was determined to be 1.03 .

\subsection{The myristoyl-end capped Jeffamine/water system}

The phase diagram of the system ED900Myr/water was studied between 10 and $70{ }^{\circ} \mathrm{C}$ along all the surfactant concentration range and it is presented in Figure 1. The diagram presents an expanded micellar domain, for temperatures below the cloud point curve. The cloud point temperature for this system is found at $50{ }^{\circ} \mathrm{C}$ for $2 \mathrm{wt} \%$ of amphiphile. Above this point, two micellar phases coexist. The size of micelles was also measured by DLS experiments. The results indicate that micelles have a diameter of about $7.0 \mathrm{~nm}$. Moreover, as measured by tensiometry, the addition of modified ED900 decreases the surface tension of water up to $31 \mathrm{mNm}^{-1}$ at a very low concentration $\left(1 \mu \mathrm{mol} \cdot \mathrm{L}^{-1}\right)$. The structure of the micelles was investigated by SAXS. The experiments were performed at $20{ }^{\circ} \mathrm{C}$ on micellar solutions with different surfactant concentrations. The experimental curves are displayed in Figure 2a. The scattering intensities are normalized to the same incident primary beamline and with respect to the surfactant concentration. All the curves exhibit a maximum at $1 \mathrm{~nm}^{-1}$ and are overlapped from this value. At low $\mathrm{q}$ values $\left(\mathrm{q}<0.3 \mathrm{~nm}^{-1}\right)$ the intensities increase with increasing concentration due to the interparticle effect ${ }^{40}$. Therefore, only the curve scattering obtained at $5 \mathrm{wt} \%$ was evaluated with the Generalized Indirect Fourier Transform (GIFT) analysis $^{[41,42]}$ (Figure 2b). The corresponding pair-distance distribution function (PDDF) P(r) is given in Figure 2c. The curve exhibits pronounced maximum and minimum on the left side, which is regarded as the typical feature of a core-shell type particle ${ }^{41-43}$, and which provides 
quantitative information about the internal structure of the micelles. The inflection point between the maximum and the minimum gives the radius of the hydrophobic core. Moreover, the PDDF function which represents a histogram of the distances inside particle provides the maximum dimension of the particle as well as its shape. A symmetric maximum on the right side indicates the presence of spherical aggregates, whereas a long tail at high $\mathrm{r}$ values features for elongated cylindrical particle. Taking into account these considerations, one can conclude that ED900Myr micelles are slightly elongated, with a maximum size of $7 \mathrm{~nm}$, which is in perfect agreement with the hydrodynamic particle diameter measured by DLS. The radius of the hydrophobic core is about $2 \mathrm{~nm}$ and matched well with the one obtained from the deconvolution of the $\mathrm{P}(\mathrm{r})$ function into the radial electron density $\Delta \rho(\mathrm{r})$ (Figure $2 \mathrm{~d}$ ). More precisely, the radius of the core formed by the myristoyl chains is about $1 \mathrm{~nm}$, which corresponds to the lowest value of $\Delta \rho(\mathrm{r})$, in agreement with the theoretical electronic density value estimated ( $\left.\rho_{\text {Alk }} \approx 276 \mathrm{e} / \AA^{3}\right)$. The thickness of the propylenoxide (PO) shell is also about $1 \mathrm{~nm}$ and $\Delta \rho(\mathrm{r})$ progressively increases to the water value. The values of the calculated theoretical electronic densities show the same profile as the modelized one since $\rho_{\mathrm{PO}} \approx$ $332 \mathrm{e} / \AA^{3}, \rho_{\mathrm{EO}} \approx 371 \mathrm{e} / \AA^{3}$ and $\rho_{\text {water }} \approx 334 \mathrm{e} / \AA^{3}$ (Figure 2e). If one considers both extended myristoyl chains of about $2 \mathrm{~nm}$ and 3 PO units $(\approx 1 \mathrm{~nm})$, this suggests that the alkyl chains are disordered, whereas the PO units are rather extended.

When the weight percent of ED900Myr is increased from 47 to $70 \mathrm{wt} \%$, a characteristic optically anisotropic hexagonal phase is detected. The hexagonal symmetry is confirmed by SAXS measurements. From geometrical considerations, the distance d associated to the first peak is related to the hydrophobic radius $\mathrm{R}_{\mathrm{H}}$ (alkyl chains $+\mathrm{PO}$ units) by the relation $(1)^{44}$ :

$$
\frac{\mathrm{V}_{\mathrm{B}}}{\mathrm{V}_{\mathrm{S}}+\alpha \mathrm{V}_{\mathrm{W}}}=\frac{\pi \sqrt{3} \mathrm{R}_{\mathrm{H}}^{2}}{2 \mathrm{~d}_{100}^{2}}
$$


where $\alpha$ stands for the number of water molecules per surfactant molecule, $V_{B}$ is the hydrophobic molar volume $\left(935 \mathrm{~cm}^{3} \cdot \mathrm{mol}^{-1}\right) . \mathrm{V}_{\mathrm{B}}$ is calculated from the molar volumes of the two myristoyl chains and of the six PO units. $V_{S}$ is the surfactant molar volume (1392 $\left.\mathrm{cm}^{3} \cdot \mathrm{mol}^{-1}\right)$ and $\mathrm{V}_{\mathrm{w}}$ is the water molar volume $\left(18 \mathrm{~cm}^{3} \cdot \mathrm{mol}^{-1}\right)$. The cross-sectional area $\mathrm{S}$ can then be deduced from the following relation $(2)^{44}$ :

$$
\mathrm{S}=\frac{2 \mathrm{~V}_{\mathrm{B}}}{\mathrm{R}_{\mathrm{H}} \mathrm{N}_{\mathrm{A}}}
$$

An increase in the d-spacing from 5 to $6 \mathrm{~nm}$ and thus, in the cell parameter is noted with increasing water content from 35 to $50 \mathrm{wt} . \%$ (SI 2). This is due to the hydration of the head group and to a possible water film surrounding the surfactant. The hydrophobic radius is constant with $\alpha$, and equal to $1.94 \mathrm{~nm} \pm 0.02 \mathrm{~nm}$. The surface occupied by the surfactant molecule in the interface is found to be $1.45 \mathrm{~nm}^{2} \pm 0.02 \mathrm{~nm}^{2}$ along the entire hexagonal phase. From these values, one can see that, as observed in the case of micelles, in $\mathrm{H}_{1}$ the two alkyl chains are assembled into the core of the cylinders and that the PO units form a corona around the core forcing the amphiphilic molecules to fold in half, over on themselves (Figure 2e). The value of the hydrophobic radius corresponds exactly to the one found for the micelles. If the surfactant concentration is increased beyond $75 \mathrm{wt} \%$, a gel phase $\left(\mathrm{L}_{\beta}\right)$ appears. Its structure is well described in literature and corresponds to a stacking of bilayers, whose alkyl chains are solid. In fact, in the low q-range of the diffraction patterns, up to five reflections are observed, with a relation between them of 1:2:3:4:5 (Figure 3A). One can note that the first reflection is less intense than the second one. This is probably due to the weak intensity of the form factor at the $\mathrm{q}$ value corresponding to the second reflection. Taking into account geometrical considerations, one can calculate the area per molecule $\mathrm{S}$ with the following relation $(3)^{44}$ :

$$
\mathrm{S}=\frac{\mathrm{V}_{\mathrm{S}}+\alpha \mathrm{V}_{\mathrm{w}}}{\mathrm{N} \cdot \mathrm{d}_{01}}
$$


where $d_{01}$ is the first order repetition distance of the $L_{\beta}$. Considering that the layer spacing comprises one extended amphiphilic molecule including corresponding water content, the value of the area per molecule for the sample containing $85 \mathrm{wt} \%$ of ED900Myr is $\mathrm{S}=$ $0.246 \mathrm{~nm}^{2}$

In the WAXS region, two diffraction lines at $0.38 \mathrm{~nm}$ and $0.41 \mathrm{~nm}$ are observed and feature for an orthorhombic perpendicular packing $(\mathrm{O} \perp)$ of the hydrocarbon chains ${ }^{45}$ (Figure $\left.3 \mathrm{~B}\right)$. According to previously indexing results ${ }^{46}$, these peaks correspond to the in-plane $\mathrm{d}_{110}$ and $\mathrm{d}_{020}$ and give the following lattice parameters: $\mathrm{a}=0.51 \mathrm{~nm}, \mathrm{~b}=0.74 \mathrm{~nm}$ and $\mathrm{c}=0.255 \mathrm{~nm}$. Moreover, another doublet appears in the middle q-range, at $0.78 \mathrm{~nm}$ and $0.74 \mathrm{~nm}$, which could correspond to an in-plane super structure of the orthorhombic cell. From the wide-angle diffraction lines in the $\mathrm{L}_{\beta}$ phase, an area per chain of $0.185 \mathrm{~nm}^{2}$ can also be calculated with the equation below $(4)^{46,47}$ :

$$
A_{c}=\frac{d_{110} \cdot d_{020}}{\left.\sqrt{1-(} d_{110} / 2 d_{020}\right)^{2}}
$$

These two values $\mathrm{S}$ and $\mathrm{A}_{\mathrm{c}}$ are in good agreement with an extended molecule, contrarily to the hexagonal phase, where the molecules are self-folded; such a scenario would give a molecular area of $0.49 \mathrm{~nm}^{2}$ in the gel phase.

This phase melts at $25^{\circ} \mathrm{C}$, leading directly to an inverse micellar phase $\left(\mathrm{L}_{2}\right)$.

\section{3 .Silica mesoporous materials}

Micellar solutions of ED900Myr were then used as template to prepare the silica materials through the self-assembly mechanism. Syntheses have been carried out under neutral conditions. The TMOS has been added at $20{ }^{\circ} \mathrm{C}$. First, the hydrothermal treatment was performed during 24 hours at $100{ }^{\circ} \mathrm{C}$. Indeed, it is reported that under these conditions, a hexagonal pore ordering can be obtained from the self-assembly mechanism by using 
different kinds of surfactants ${ }^{13,32,48,49}$. We have investigated the effect of the variation of both the amphiphile concentration and the ED900Myr/TMOS molar ratio $(\mathrm{R})$ on the mesopore ordering. As regards the samples synthesized with a $5 \mathrm{wt} \%$ of modified Jeffamine, the SAXS patterns of the materials prepared with a molar ratio higher than 0.2 exhibit only a single broad reflection ( $\mathrm{SI} 3 \mathrm{Bb}-\mathrm{e}$ ), which indicates the formation of a disordered structure. If a higher quantity of the inorganic precursor ( $\mathrm{R}$ lower than 0.2 ) is introduced, no line is observed on the SAXS pattern (SI3Ba), indicating that the recovered compounds exhibit a complete randomly oriented pore structure. The $\mathrm{N}_{2}$ adsorption-desorption isotherms and the pore size distributions for the materials are represented in Figure 4. All materials exhibit a type IV isotherm, characteristic of mesoporous materials according to the IUPAC classification ${ }^{50}$. A H2 type hysteresis loop, in which the desorption branch is steep, but adsorption branch is more or less sloping, is observed. The H2 type hysteresis loop is often encountered for disordered materials with a wormhole structure. The pore size distributions are quite large and centered at $14 \mathrm{~nm}$ at $\mathrm{R} \geq 0.2$; they are narrower for the higher ratios. A similar behavior is noted for the silica prepared with 3 wt \% (SI3A) or 10 wt \% (SI3C) of ED900Myr. By contrast, when a $20 \mathrm{wt} \%$ of ED $900 \mathrm{Myr}$ is employed to prepare the silica materials, the situation is quite different. Indeed, whatever the value of $\mathrm{R}$, no reflection line is detected on the SAXS pattern (SI3D). Depending on the synthesis conditions, the specific surface area varies from 286 to $686 \mathrm{~m}^{2} / \mathrm{g}$ (SI 4).

The SAXS results show that the best patterns were obtained at lower ED900Myr concentrations $(3,5$ and then $10 \mathrm{wt} \%)$ for $1 \geq \mathrm{R} \geq 0.2$. However, these patterns only show one single reflection centered at $\mathrm{d}=5.1 \mathrm{~nm}$ without any higher other Bragg reflections resolved, indicating a wormlike structure of the pores. The channel array can be also affected by the conditions of the hydrothermal treatment, therefore fixing the ED900Myr concentration and the ED900My/TMOS molar ratio to $5 \mathrm{wt} \%$ and 0.6 , respectively, we have 
varied both the temperature and the duration of the hydrothermal treatment. The temperatures chosen were: room temperature, 50, 60, 70, 80, 90 and $100^{\circ} \mathrm{C}$. For the lowest temperatures, the hydrothermal treatment time was extended to 44 hours for 50 and $60^{\circ} \mathrm{C}$ and 140 hours in the case of room temperature, since usually lower temperatures used in the hydrothermal treatment require longer time to structure the material. The SAXS patterns (Figure 5A) clearly show an improvement of the hexagonal structure when the temperature is lowered. In fact, the best results are obtained when performing the hydrothermal treatment at $50{ }^{\circ} \mathrm{C}$ for 44 hours (Figure 5Ab) and at room temperature for 140 hours (Figure 5Aa). As a matter of fact, under these conditions three reflection lines located at 5.2, 3.0 and $2.5 \mathrm{~nm}$ can be detected on the SAXS pattern. Their relative positions are $1, \sqrt{3}$ and 2, which can be attributed to the (100), (110) and (200) reflections of the hexagonal structure. According to Bragg's law, the unit cell dimension $\left(\mathrm{a}_{0}\right)$ can be calculated and found equal to $6.0 \mathrm{~nm}$. The mesopore ordering is further confirmed by the transmission electron microscopy (TEM) images (Figure 5B). Indeed, either the honeycomb-like arrangement (Figure 5Ba) or the hexagonal stacking (Figure 5Bb) of the channels is evidenced by the TEM analysis. From nitrogen adsorption-desorption measurements, we can observe that these recovered samples exhibit a type IV isotherm (Figure 6A). The specific surface area and pore volume values are respectively $1300 \mathrm{~m}^{2} / \mathrm{g}$ and $0.95 \mathrm{~cm}^{3} / \mathrm{g}$. The pore diameter distribution determined by using the $\mathrm{BJH}$ method is quite narrow and centered at ca. $3.2 \mathrm{~nm}$ (SI5). The wall thickness, deduced by subtracting the pore size from the dimension of the unit cell, is equal to $2.8 \mathrm{~nm}$. The SEM images of the sample prepared at room temperature (RT) show that the material is formed by cylindrical particles, of uniform size around $300 \mathrm{~nm}$ length and $100 \mathrm{~nm}$ section (Figure 7). If the hydrothermal treatment is performed at a higher temperature, the formation of well-ordered mesoporous molecular sieves is not favored. Indeed, only one peak is observed on the SAXS pattern (Figure 5Ae-i), meaning that the materials adopt a wormhole-like structure. In addition, from 
Figure $6 \mathrm{~A}$, the relative pressure for which capillary condensation takes place is shifted toward higher values when the temperature increases (from 0.4 at RT up to 0.8 at $100{ }^{\circ} \mathrm{C}$ ). Since the $\mathrm{p} / \mathrm{p}_{0}$ position of the inflection point is related to the pore diameter according to Kelvin's equation, it can be inferred that an enlargement of the mean pore diameter occurs. This is confirmed by the pore size distribution, whose maximum is shifted toward higher values when the hydrothermal temperature increased from room temperature to $100{ }^{\circ} \mathrm{C}$ (SI5 and Figure 6B). At $50{ }^{\circ} \mathrm{C}$, the pore size distribution is centered at $3.8 \mathrm{~nm}$, whereas at $100{ }^{\circ} \mathrm{C}$ it is centered at $14.4 \mathrm{~nm}$. This expansion of the pore size can be interpreted as the result of a variation of the aggregation number of micelles $\left(\mathrm{L}_{1}\right.$ phase). Indeed, it is well established that, for nonionic surfactants, an increase in temperature will involve an increase in the aggregation number ${ }^{51,52}$. Thus, bigger micelles will be formed with increasing heating temperature and, consequently, materials with higher pore diameters will be recovered. The pore volume remains approximately constant around $1 \mathrm{~cm}^{3} / \mathrm{g}$ at all the temperatures considered, whereas the specific surface progressively decreases from 1300 to $400 \mathrm{~m}^{2} / \mathrm{g}$ when the temperature increases (SI6). From all the gathered results, it can be deduced that the optimal temperatures to prepare the mesoporous materials are from RT to below $70^{\circ} \mathrm{C}$. The lower the temperature, the better the mesopore ordering. We can assume that the disorganization of the mesopore network with the increase of the temperature is due to a too thin silica wall to preserve the organization after the surfactant removal by the formation of bridges between two adjacent pores as it has been shown for SBA-15 materials ${ }^{32}$. This phenomenon has also been noted in our previous work dealing with the influence of the different synthesis parameters on the properties of mesostructured silica prepared from a nonionic fluorinated surfactant basedsystem ${ }^{49}$ Moreover, according to Holmberg et al. ${ }^{53}$ at lower temperature, as the condensation rate is slower, a well-ordered structure is favored. At high temperature, the loss of the hexagonal structure can be due to an accelerated condensation of silanol groups that form an 
excess cross-linked framework. After observing that a well-ordered hexagonal mesoporous material was obtained when performing the hydrothermal treatment at a lower temperature, the molar ratio between the TMOS and ED900Myr (R) was varied for a hydrothermal treatment performed at $50{ }^{\circ} \mathrm{C}$ during 44 hours, in order to study the influence of this parameter on the mesopore ordering. In the range from 0.4 to 1 , three reflection lines located at 5.1, 2.9 and $2.6 \mathrm{~nm}$ can be detected on the SAXS pattern (SI7Ab-d). The repetition distance corresponding to the $(100)$ reflection is constant $(5.1 \mathrm{~nm})$ and thus, the cell parameter $\mathrm{a}_{0}(5.9$ $\mathrm{nm}$ ) does not depend on the quantity of TMOS used for the synthesis. The SAXS patterns of the material prepared with a molar ratio of 0.1 exhibits only a single broad reflection (SI7Aa), which indicates the formation of a disordered structure. In that case, we can assume that only a part of the silica interacts with the surfactant to form the channel arrangement and that another part precipitates to form an amorphous silica phase. Thus, the ordered pore network is diluted in a non-structured silica phase and the SAXS patterns exhibit weaker and larger diffraction peaks. For instance, Ekloff et al. ${ }^{54}$ attributed the poor hexagonal long range order of their particles obtained at surfactant/silica ratio higher than 0.66 to the polymerization of the silica source into solid amorphous silica due to the excess of surfactant. In the present study, similar arguments can be taken into account to explain the transition from a well ordered mesopore ordering to a randomly oriented pore structure when the value of $\mathrm{R}$ is diminished. The pore size varies between 3.5 and $3.9 \mathrm{~nm}$, depending on the operating conditions (SI7Bb). However, no significant differences are observed in the pore size distributions when varying the surfactant to TMOS ratio (from 0.1 to 1 ). The major difference is encountered when working at the lowest $\mathrm{R}(0.1)$, since the pore size distribution is wider and the adsorption-desorption isotherm is different. In this case the isotherm profile increases gradually with increasing relative pressures (SI7Ba), although the mean pore size remains unchanged $(\mathrm{SI} 7 \mathrm{Bb})$. The others isotherms follow the same profile, type IV, with a capillary 
condensation around $\mathrm{p} / \mathrm{p}_{0}=0.5(\mathrm{SI} 7 \mathrm{Ba})$, from which the isotherm becomes flat. The specific surface area is higher than $800 \mathrm{~m}^{2} / \mathrm{g}$ (SI8).

\section{Conclusion}

Jeffamine surfactants were already used as structure-directing porogen, but to date, only wormhole structures were obtained. Herein, we reported the first example of organized mesoporous silica from myristic-end capped Jeffamine (ED900). For a complete characterization of the newly reported surfactant (ED900Myr), the binary phase diagram was determined. The characterization of the micelles and the liquid crystals phases by SAXS show that the molecules are folded in half in order to locate the two myristoyl chains inside the core. In the hexagonal liquid crystal phase, the value of the hydrophobic radius is the same than the hydrophobic core of the micelles. No variation of the cross sectional area with the number of water molecules per surfactant molecule is noted.

Micellar solutions of ED900Myr were used as template to prepare the mesoporous materials through the self-assembly mechanism. The influence of the synthesis conditions on the properties of the mesopore ordering has been investigated. Well ordered mesoporous materials are recovered when the ED900My concentration is low $(<10 \mathrm{wt} \%)$. SAXS analysis also evidences that the hexagonal pore ordering is favored when the hydrothermal treatment is performed at low temperature. In addition, an increase in the pore diameter is noted with the raise in the hydrothermal treatment temperature.

Supporting information available: ESI-MS spectra of ED900 and ED900Myr (SI1). Structural parameters of the hexagonal phase (SI2). SAXS patterns of the materials (SI3) and textural properties (SI4) as a function of the wt \% of ED900Myr and of the ED900Myr/TMOS molar ratio. Variation of the mesopore size distribution (SI5) and textural 
properties (SI6) as a function of the hydrothermal treatment conditions. SAXS pattern, nitrogen adsorption-desorption isotherms, pore size distribution (SI7) and textural properties (S8) of the mesoporous materials synthesized with 5 wt \% ED900Myr during 44 hours at 50 ${ }^{\circ} \mathrm{C}$ as a function of the ED900Myr/TMOS molar ratio (SI8).

\section{Acknowledgements :}

Authors would like to thank Lionel Perdreau of Huntsman Surface Sciences (St Mihiel, France) for providing the Jeffamine surfactant. Authors would also like to thank Mélanie Emo for performing the X-ray measurements and for her contribution to GIFT/DECON interpretation data. Anna May would like to thank the Spanish MICINN for the financial support within the framework of the project number CTQ2008-06892-C03-03/PPQ. 


\section{References}

1 Kresge, C. T.; Leonowicz, M. E.; Roth, W. J.; Vartuli, J. C. and Beck, J. S. Ordered mesoporous molecular sieves synthesized by a liquid-crystal template mechanism Nature 1992, 359, 710-712.

2 Beck, J. S.; Vartuli, J. C.; Roth, W. J.; Leonowicz, M. E.; Kresge, C. T.; Schmitt, K. D.; Chu, C. T. W.; Olson, D. H.; Sheppard, E. W.; McCulle, S. B.; Higgins, J. B. and Schlender, J. L. A new family of mesoporous molecular-sieves prepared with liquidcrystal templates J. Am. Chem. Soc. 1992, 114, 10834-10843.

3 Zimny, K.; Caretert, C.; Stébé, M. J. and Blin, J. L. Multitechnique investigation of mesoporous titanosilicate materials prepared from both the self-assembly and the liquid crystal mechanisms J. Phys. Chem. C 2011, 115, 8684-8692.

4 Botella, P.; Corma, A. and Quesada, M. Synthesis of ordered mesoporous silica templated with biocompatible surfactants and applications in controlled release of drugs J. Mater. Chem. 2012, 22, 6394-6401.

5 Park, S. Y.; Barton, M. and Pendleton, P. Mesoporous silica as a natural antimicrobial carrier Colloid Surface A 2011, 385, 256-261.

6 Zhang, X.; Thavasi, V.; Mhaisalkar, S. G. and Ramakrishna, S. Novel hollow mesoporous 1D $\mathrm{TiO} 2$ nanofibers as photovoltaic and photocatalytic materials Nanoscale 2012, 4, 1707-1716.

7 Braganca, L. F. F. P. G.; Ojeda, M.; Fierro, J. L. G. and Pais da Silva, M. I. Bimetallic Co-Fe nanocrystals deposited on SBA-15 and HMS mesoporous silicas as catalysts for Fischer-Tropsch synthesis Appl. Catal. A-Gen. 2012, 423-424, 146-153.

8 Blin, J. L.; Gérardin, C.; Carteret, C.; Rodehüser, L.; Selve, C. and Stébé, M. J. Direct one-step immobilization of glucose oxidase in well-ordered mesostructured silica using a nonionic fluorinated surfactant Chem. Mater. 2005. 17, 1479-1486. 
9 Wan, Y. and Zhao, D. On the controllable soft-templating approach to mesoporous silicates Chem. Rev. 2007, 107, 2821-2860.

10 Zhao, D.; Huo, Q.; Feng, J.; Chmelka, B. F. and Stucky, G. D. Nonionic triblock and star diblock copolymer and oligomeric surfactant syntheses of highly ordered, hydrothermally stable, mesoporous silica structures J. Am. Chem. Soc. 1998, 120, 6024-6036.

11 Firouzi, A.; Kumar, D.; Bull, L. M.; Besier, T.; Sieger, P.; Huo, Q.; Walker, S. A.; Zasadzinski, J. A.; Glinka, C. and Stucky, G. D. Cooperative organization of inorganic-surfactant and biomimetic assemblies Science 1995, 267, 1138-1143.

12 Lee, Y. S.; Sujardi, D and Rathman, J. F. Effects of aluminate and silicate on the structure of quaternary ammonium surfactant aggregates Langmuir 1996, 12, 62026210.

13 Blin, J. L.; Otjacques, C.; Herrier G. and Su, B. L. International J. Inorganic Mater. 2001, 3, 75 .

14 Attard, G. S.; Glyde, J. C. and Göltner, C. G. Liquid-crystalline phases as templates for the synthesis of mesoporous silica Nature 1995, 378, 366-368.

15 El-Safty, S. A. and Hanaoka, T. Microemulsion liquid crystal templates for highly ordered three-dimensional mesoporous silica monoliths with controllable mesopore structures Chem. Mater. 2004, 16, 384-400.

16 El-Safty; Kiyozumi, Y.; Hanaoka, T. and Mizukami, F. Controlled design of ordered and disordered pore architectures, geometries, and dimensions of HOM-type mesostructured monoliths and their hydrothermal stabilities J. Phys. Chem. C 2008, $112,5476-5489$.

17 Feng, P.; Bu, X.; Stucky, G. D. and Pine, D. J. Monolithic mesoporous silica templated by microemulsion liquid crystals J. Am. Chem. Soc. 2000, 122, 994-995. 
18 Zimny, K.; Blin J. L.; Stébé, M. J. Ordered Mesoporous Silica Templated by Nonionic Fluorinated Liquid Crystals J. Phys. Chem. C 2009, 113, 11285-11293.

19 Wan, Y.; Shi, Y. and Zhao, D. Designed synthesis of mesoporous solids via nonionicsurfactant-templating approach Chem. Commun. 2007, 9, 897-926.

20 Huo, Q.; Margolese, D. I. and Stucky, G. D. Surfactant control of phases in the synthesis of mesoporous silica-based materials Chem. Mater. 1996, 8, 1147-1160.

21 Bagshaw, S. A.; Prouzet, E. and Pinnavaia, T. J. Templating of Mesoporous Molecular Sieves by Nonionic Polyethylene Oxide Surfactants Science 1995, 269, 1242-1244.

22 Prouzet, E. and Pinnavaia, T. J. Assembly of mesoporous molecular sieves containing wormhole motifs by a nonionic surfactant pathway: Control of pore size by synthesis temperature Angew. Chem. Int. Ed. Engl. 1997, 36, 516-518.

23 Blin, J. L.; Lesieur, P. and Stébé, M. J. Nonionic fluorinated surfactant: Investigation of phase diagram and preparation of ordered mesoporous materials Langmuir 2004, $20,491-498$.

24 Blin, J. L. and Stébé, M. J. Effect of fluorocarbon addition on the structure and pore diameter of mesoporous materials prepared with a fluorinated surfactant Microporous and Mesoporous Mater. 2005, 87, 67-76.

25 Tan, B.; Dozier, A.; Lehmler, H. J.; Knutson, B. and Rankin, S. E. Elongated silica nanoparticles with a mesh phase mesopore structure by fluorosurfactant templating Langmuir 2004, 20, 6981-6984.

26 Rankin, S. E.; Tan, B.; Lehmler, H. J.; Hindman, K. P. and Knutson, B. Well-ordered mesoporous silica prepared by cationic fluorinated surfactant templating Microporous and Mesoporous Mater. 2004, 73, 197-202. 
27 Esquena, J.; Rodriguez, C.; Solans, C. and Kunieda, H. Formation of mesostructured silica in nonionic fluorinated surfactant systems Microporous and Mesoporous Mater. 2006, 92, 212-219.

28 Michaux, F.; Carteret, C.; Stébé, M. J. and Blin, J. L. Hydrothermal stability of mesostructured silica prepared using a nonionic fluorinated surfactant Microporous and Mesoporous Mater. 2008, 116, 308-317.

29 Zhao, D.; Feng, J.; Huo, Q.; Melosh, N.; Fredrickson, G. H.; Chmelka, B. F. and Stucky, G. D. Triblock copolymer syntheses of mesoporous silica with periodic 50 to 300 angstrom pores Science 1998, 279, 548-552.

30 Yu, C.; Fan, J.; Tian, B.; Stucky, G. D. and Zhao, D. Synthesis of mesoporous silica from commercial poly(ethylene oxide)/poly(butylene oxide) copolymers: Toward the rational design of ordered mesoporous materials J. Phys. Chem. B 2003, 107, 1336813375.

31 Impéror-Clerc, M.; Davidson, P. and Davidson, A. Existence of a microporous corona around the mesopores of silica-based SBA-15 materials templated by triblock copolymers J. Am. Chem. Soc. 2000, 122, 11925-11933.

32 Galarneau, A.; Cambon, H.; Di Renzo, F.; Ryoo, R.; Choi, M. and Fajula, F. Microporosity and connections between pores in SBA-15 mesostructured silicas as a function of the temperature of synthesis New J. Chem. 2003, 27, 73-79.

33 Flodström, K. and Alfredsson, V. Influence of the block length of triblock copolymers on the formation of mesoporous silica Microporous and Mesoporous Mater. 2003, 59, $167-176$.

34 Kipkemboi, P.; Fogden, A.; Alfredsson, V. and Flodström, K. Triblock copolymers as templates in mesoporous silica formation: Structural dependence on polymer chain length and synthesis temperature Langmuir 2001, 17, 5398-5402. 
35 Benamor, T.; Vidal, L.; Lebeau, B. and Marichal, C. Influence of synthesis parameters on the physico-chemical characteristics of SBA-15 type ordered mesoporous silica Microporous and Mesoporous Mater. 2012, 153, 100-114.

36 Park, I.; Wang, Z.; Pinnavaia, T. J. Assembly of large-pore silica mesophases with wormhole framework structures from alpha,omega-diamine porogens Chem. Mater. 2005, 17, 383-386.

37 Park, I. and Pinnavaia, T. J. Large-pore mesoporous silica with three-dimensional wormhole framework structures Microporous and Mesoporous Mater. 2009, 118, 239244.

38 Hossain, K. Z. and Sayari, A. Synthesis of onion-like mesoporous silica from sodium silicate in the presence of alpha,omega-diamine surfactant Microporous and Mesoporous Mater. 2008, 114, 387-394.

39 Barret, E. P.; Joyner, L. G. and Halenda, P. P. The determination of pore volume and area distributions in porous substances. I. Computations from nitrogen isotherms $J$. Am. Chem. Soc. 1951, 73, 373-380.

40 Löf, D.; Tomsic, M.; Glatter, O.; Fritz-Popovski, G. and Schillen, K. Structural Characterization of Nonionic Mixed Micelles Formed by C12EO6 Surfactant and P123 Triblock Copolymer J. Phys. Chem. B 2009, 113, 5478-5786.

41 Brunner-Popela, J. and Glatter, O. Small-angle scattering of interacting particles. I. Basic principles of a global evaluation technique J. Appl. Crystallogr. 1997, 30, 431442.

42 Varade, D.; Ushiyama, K.; Shrestha, L. K. and Aramaki, K. Wormlike micelles in Tween-80/CmEO3 mixed nonionic surfactant systems in aqueous mediaJ. Colloid Interface Sci. 2007, 312, 489-497. 
43 Weyerich, B.; Brunner-Popela, J. and Glatter, O.; Small-angle scattering of interacting particles. II. Generalized indirect Fourier transformation under consideration of the effective structure factor for polydisperse systems J. Appl. Crystallogr. 1999, 32, $197-$ 209.

44 Alibrahim, M.; Stébé, M. J., Dupont, G. and Ravey, J. C. Effect of an ionic surfactant on the phase behavior of a nonionic surfactant-based system J. Chim. Phys. 1997, 94, 1614-1633.

45 Food Emulsions, K. Larsson, E. Friberg Eds., Marcel Dekker, 1990.

46 Vincent, J. M. and Skoulios, A. "Gel" and "coagel." III. "Gel" investigation in the equimolecular mixture potassium stearate-n-octadecanol Acta Cryst 1966, 20, 447451.

47 Mannock, D. A.; Collins, M. D.; Kreichbaum, M.; Harper, P. E.; Gruner, S. M. and McElhaney, R. N. The thermotropic phase behaviour and phase structure of a homologous series of racemic $\beta$-D-galactosyl dialkylglycerols studied by differential scanning calorimetry and X-ray diffraction Chem. Phys. Lipids 2007, 148, 26-50.

48 Galarneau, A.; Nader, M.; Guenneau, F.; Di Renzo, F. and Gedeon, A. Understanding the Stability in Water of Mesoporous SBA-15 and MCM-41 J. Phys. Chem. C 2007, $111,8268-8277$.

49 Michaux, F.; Stébé, M. J. and Blin, J. L. Systematic investigation of the synthesis parameters driving the preparation of mesoporous materials using a nonionic fluorinated surfactant Microporous and Mesoporous Mater. 2012, 151, 201-210.

50 Sing, K. S. W.; Everett, D. H.; Haul, R. A. W.; Moscou, L.; Pierotti, R. A.; Rouquerol, J. and Siemieniewska, T. Reporting physisorption data for gas/solid systems with special reference to the determination of surface area and porosity (Recommendations 1984) IUPAC, Pure and Appl. Chem. 1985, 57, 603-619. 
51 Zana, R. and Weill, C. Effect of temperature on the aggregation behavior of nonionic surfactants in aqueous solutions $J$ Phys. Lett. 1985, 46, 953-960.

52 Zulauf, M.; Weckström, K.; Hayter, J. B.; Degiorgio, V. and Corti, M. Neutron scattering study of micelle structure in isotropic aqueous solutions of poly(oxyethylene) amphiphiles J. Phys. Chem. 1985, 89, 3411-3417.

53 Holmberg, K. Surfactant-templated nanomaterials synthesis J. Colloid Interface Sci. 2004, 274, 355-364.

54 Schulz-Ekloff, G.; Rathouskỷ and Zukal, Controlling of morphology and characterization of pore structure of ordered mesoporous silicasA. Microporous and Mesoporous Mater. 1999, 27, 273-285. 


\section{Figure captions}

Figure 1: Phase diagram of the system ED900Myr/water. Notation: $\mathrm{L}_{1}$ : direct micellar phase, $\mathrm{H}_{1}$ : hexagonal phase, $\mathrm{L}_{\beta}$ : gel-phase, $\mathrm{L}_{2}$ : reverse micellar phase.

Figure 2: (a) Experimental SAXS spectra (normalized with regard to the concentration) of ED900Myr micelles at 5, 10 and $20 \mathrm{wt} \%$ in $\log -\log$ representation. All measurements were performed at $20^{\circ} \mathrm{C}$; (b) experimental and calculated (GIFT) SAXS spectra of ED900Myr at a concentration of $5 \mathrm{wt} \%$ in semilogarithmic representation; (c) corresponding pair-distance distribution function of $5 \mathrm{wt} \%$ ED900Myr obtained with GIFT analysis; (d) excess electron density $\Delta \rho(r)$ as a function of the radial distance (r) of $5 \mathrm{wt} \%$ ED900Myr obtained with DECON program; (e) schematic representation of the theoretically estimated electronic density in the core-shell micelle.

Figure 3: Diffraction patterns of a $\mathrm{L}_{\beta}$ phase at $85 \mathrm{wt} \%$ of ED900Myr and $10{ }^{\circ} \mathrm{C}(\mathrm{A})$ and in-plane lateral organization of hydrophobic chains (B).

Figure 4: Adsorption isotherms (A) and pore size distribution (B) of mesoporous materials formed from a $5 \mathrm{wt} \%$ ED900Myr solution with a ED900Myr/TMOS molar ratio (R) equal to $\mathbf{\square}: 0.1 ; 0: 0.2 ; \boldsymbol{\Delta}: 0.4 ; \star \star *: 0.6$ and $\diamond: 1$. Materials are prepared at $100{ }^{\circ} \mathrm{C}$ during 24 hours.

Figure 5: A: SAXS patterns of the mesoporous materials formed from a $5 \mathrm{wt} \%$ ED900Myr solution with $\mathrm{R}=0.6$ at different hydrothermal treatment conditions a: 140 hours at room temperature; b: 44 hours at $50{ }^{\circ} \mathrm{C}$; c: 24 hours at $50{ }^{\circ} \mathrm{C}$; d: 44 hours at $60{ }^{\circ} \mathrm{C} ; 24$ hours at e: 60 , f: $70, \mathrm{~g}: 80$, h: 90 and i: 100 ${ }^{\circ} \mathrm{C}$.

B: Representative TEM micrographs of samples prepared at room temperature during 140 hours (a) and at $50^{\circ} \mathrm{C}$ during 44 hours (b). 
Figure 6: Variation of the nitrogen adsorption desorption isotherms (A) and the pore diameter (B) as a function of the hydrothermal treatment conditions. Mesoporous materials are synthesized from a 5 wt \% ED900Myr solution with $\mathrm{R}=0.6$ at room temperature for 140 hours $(\star), 50{ }^{\circ} \mathrm{C}$ for 24 hours $(\nabla), 80{ }^{\circ} \mathrm{C}$ for 24 hours $(\mathbf{A})$ and $100{ }^{\circ} \mathrm{C}$ for 24 hours $(\boldsymbol{\square})$.

Figure 7: Representative SEM images of the mesoporous materials prepared at room temperature during 140 hours. 


\section{Figure 1}

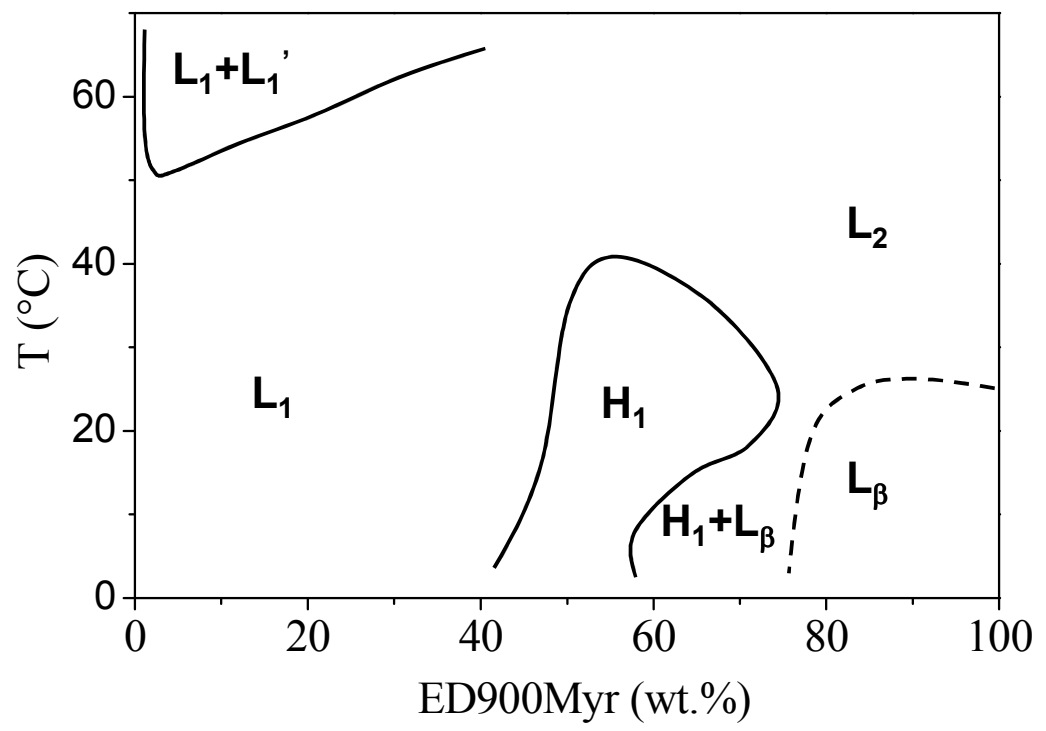


Figure 2
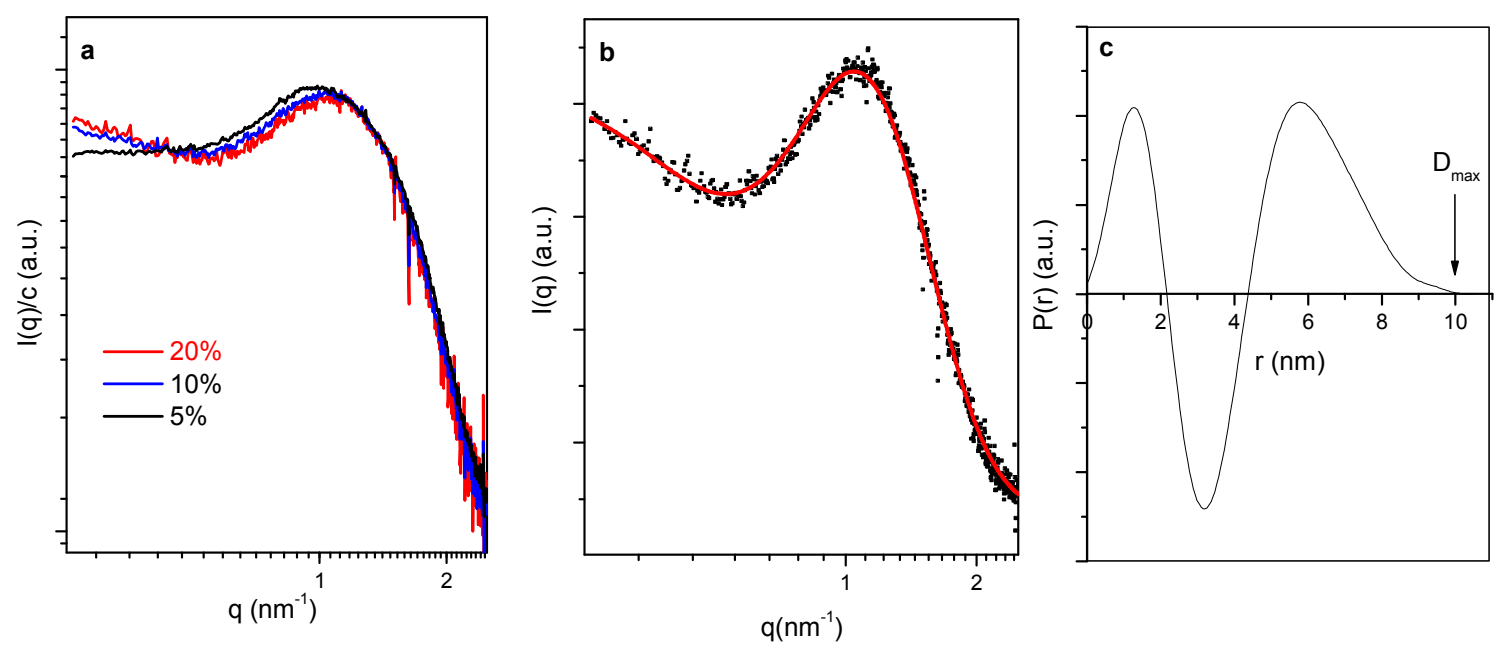

20

21

22

23

24

25

26

27

28

29

30

31

32

33

34

35

36

37

38

39

40

41

42

43

44

45

46

47

48

49

50

51

52

53

54

55

56

57

58

59
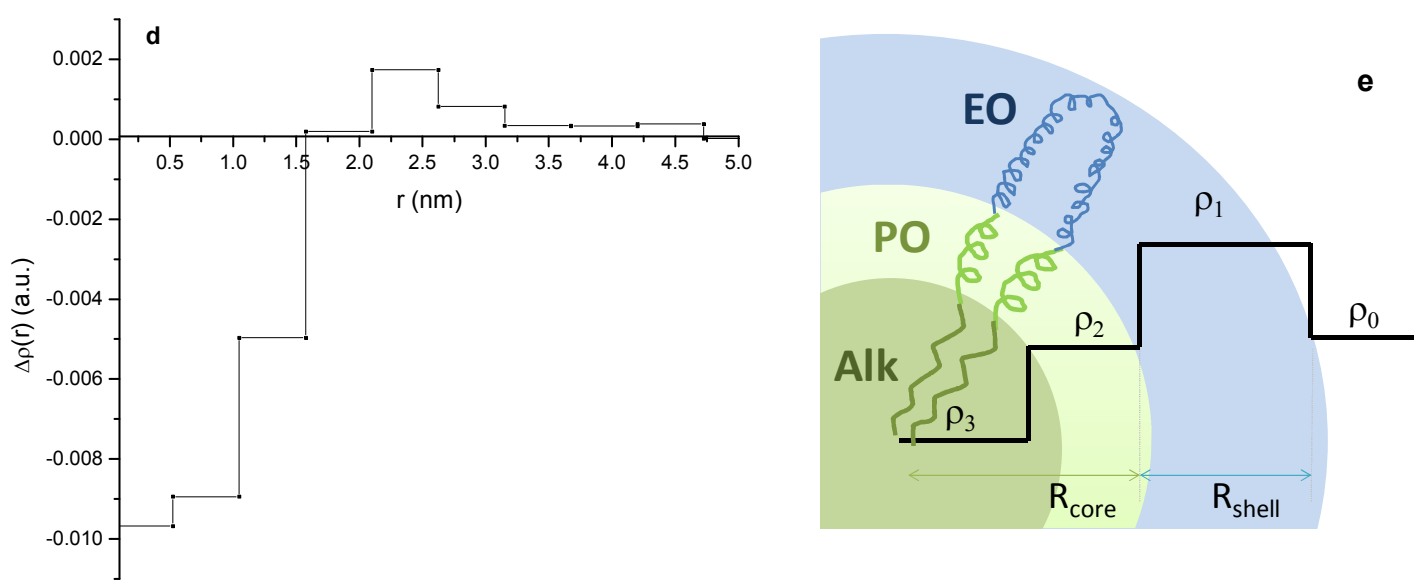

60 
1

2

3

4

5

6

7

8

9

10

11

12

13

14

15

16

17

18

19

20

21

22

23

24

25

26

27

28

29

30

31

32

33

34

35

36

37

38

39

40

41

42

43

44

45

46

47

48

49

50

51

52

53

54

55

56

57

58

59

60

Figure 3

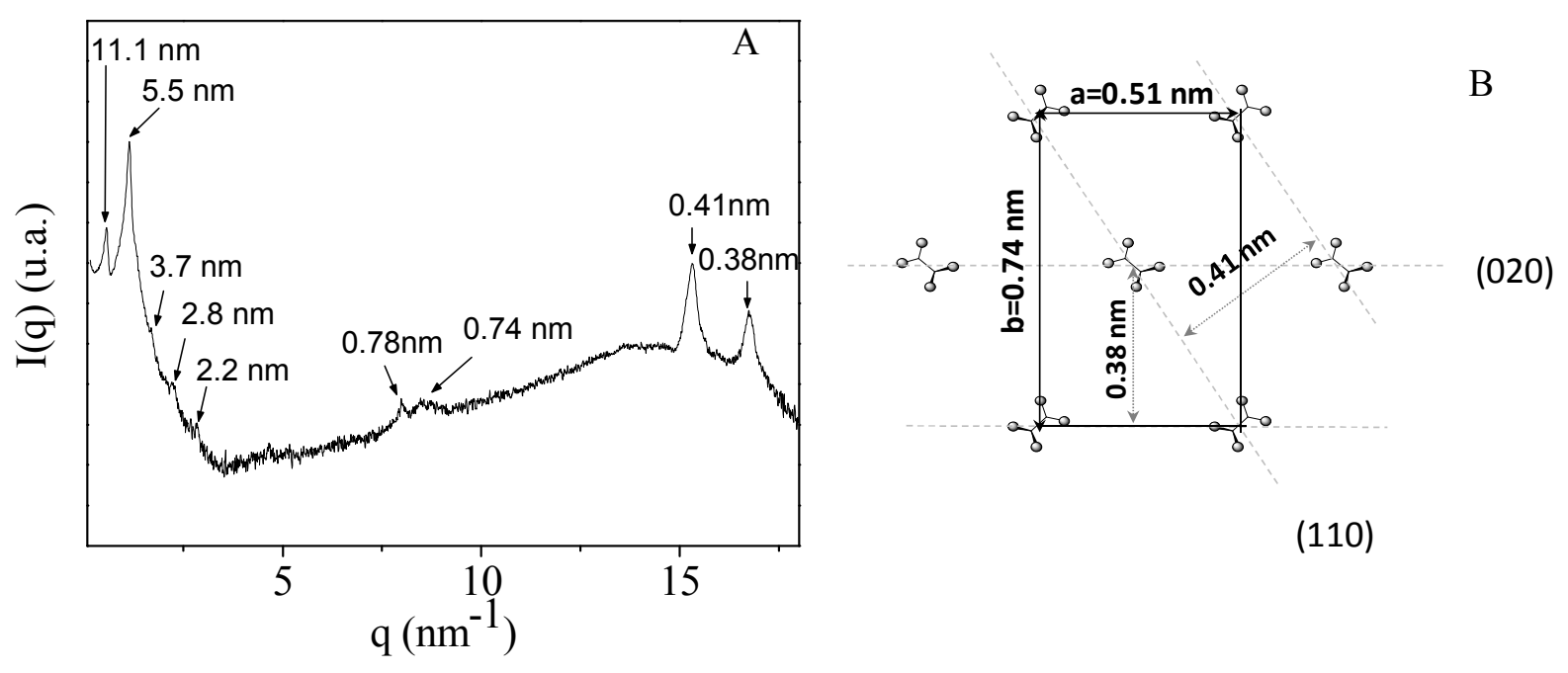




\section{Figure 4}
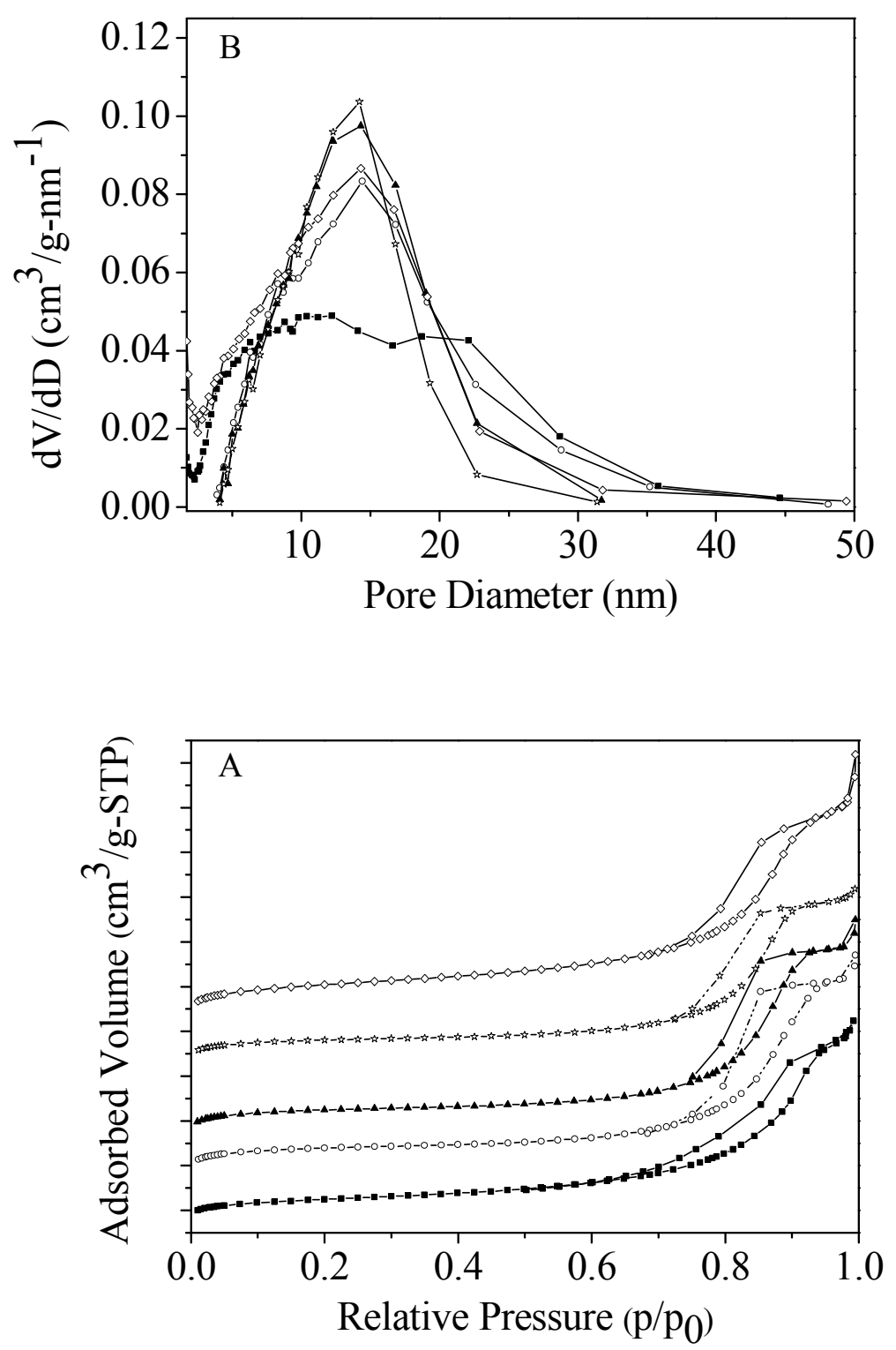

ACS Paragon Plus Environment 
Figure 5
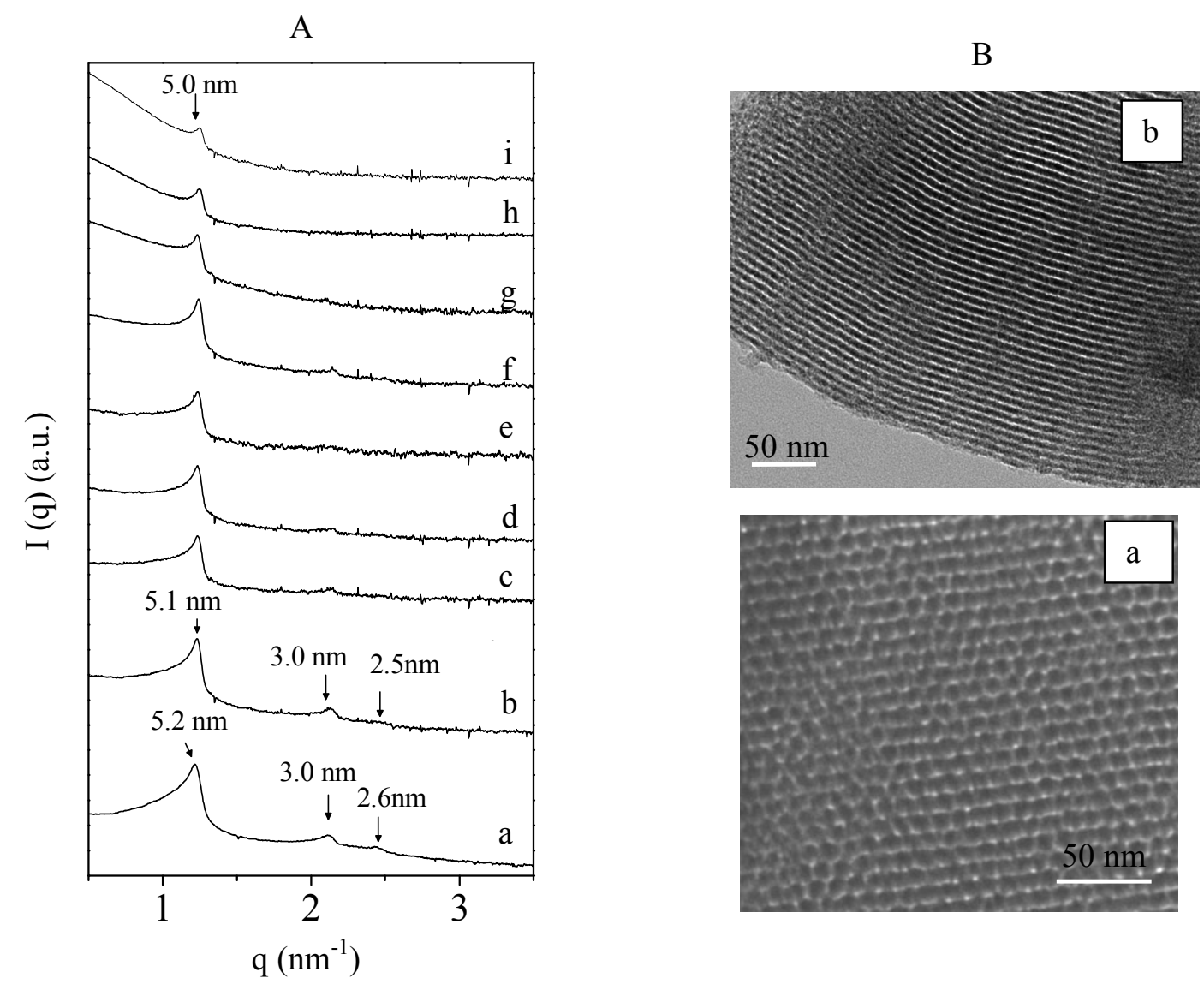

31

32

33

34

35

36

37

38

39

40

41

42

43

44

45

46

47

48

49

50

51

52

53

54

55

56

57

58

59

60 


\section{Figure 6}
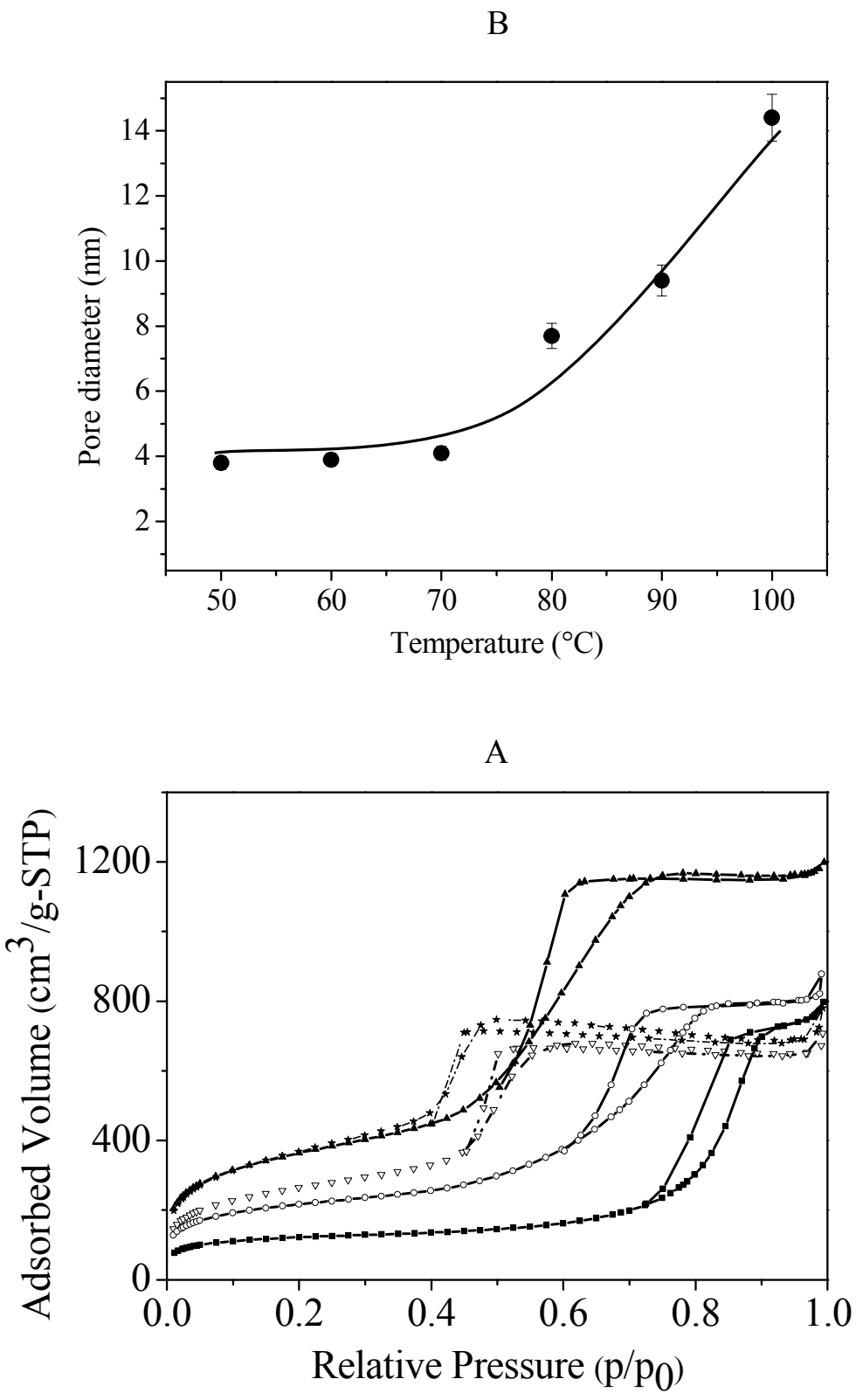

ACS Paragon Plus Environment 


\section{Page 33 of 34}

Figure 7
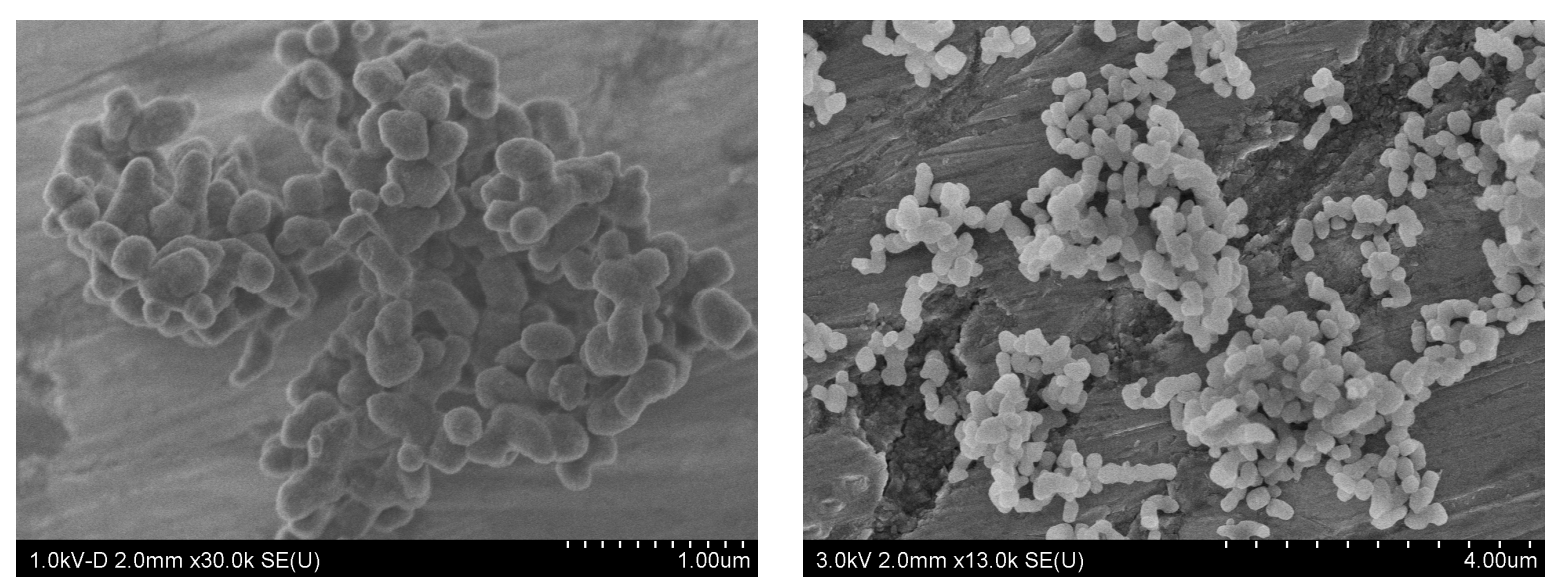

1

2

4

5

6

9

10

11

12

13

14
15

16

17

18

19

20

21

22

23

24

25

26

27

28

29

30

31

32

33

34

35

36

37

38

39

40

41

42

43

44

45

46

47

48

49

50

51

52

53

54

55

56

57

58

59

60 


\section{Graphical abstract}

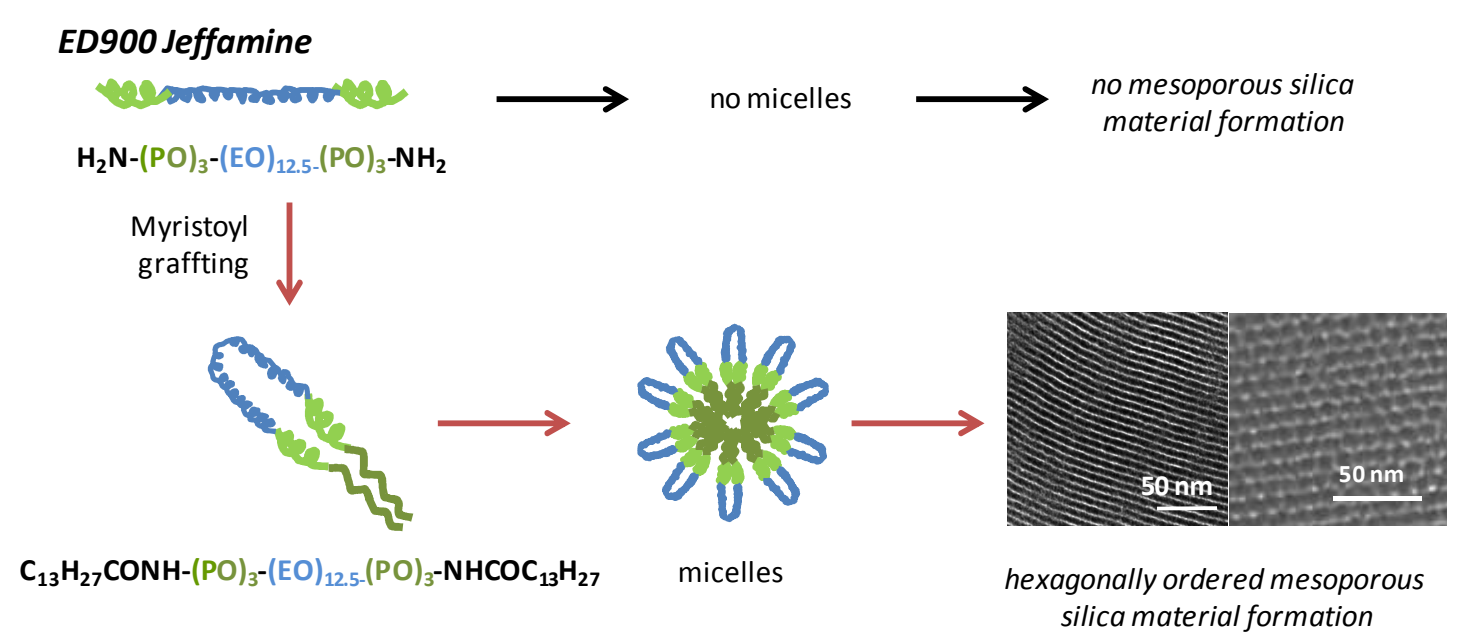

